\title{
NGHIÊN CỨU NHẬN DẠNG CÁC CỰC VỊ THẾ ĐỐI VỚI GIÁ ĐẤT Ở ĐÔ TH!̣ TẠI QUẬN CẦU GIÂYY THEO TIẾP CẬN VI THẾ - CHẤT LƯỢNG
}

\author{
BÙI NGỌC TÚ, LÊ PHƯƠNG THÚY, PHẠM LÊ TUÂN, TRẦN QUỐC BÌNH \\ Khoa Địa lý, Truò̀ng Đại học Khoa học Tụ nhiên, ĐHQGHN
}

\section{Tóm tắt}

Định giá đất đóng vai trò quan trọng trong công tác quản lý tài chính về đất đai và nhận được nhiều sụ quan tâm của xã hội và các co quan quản lý. Hiện nay, có nhiều cách tiếp cận khác nhau về định giá đất, trong đó có cách tiếp cận sư dụng lý thuyết Vị thế - Chất lượng (VT-CL). Xác định cưc vị thế là một bước quan trọng trong phuơng pháp định giá đất theo tiếp cận VT-CL. Nghiên cưu này đặt muc tiêu nhận dạng các cực vị thế đối với giá đất ở đô thị trên địa bàn quận Cầu Giấy. Với bộ dũ liệu gồm 452 mẫu điều tra trong nhũng năm gần đây và 20 yếu tố ảnh hưởng tới giá đất được nghiên cưu, nhóm tác giả đã chỉ ra được 02 cục vị thế đối với giá đất ở đô thị trên địa bàn nghiên cứu là công viên Cầu Giấy và khu đô thị mới Trung Hòa - Nhân Chính.

\section{Mở đầu}

Quá trình đô thị hóa tại các địa phương đang diễn ra ngày càng mạnh mẽ. Điều này làm cho đất đai biến động đáng kể và nhu cầu về giao dịch đất đai ngày càng tăng cao. Chính vì vậy, việc xác định giá đất ở đô thị đang ngày càng được quan tâm tại nhiều khu vực, trong đó có quận Cầu Giấy. Hiện nay có nhiều cách tiếp cận khác nhau trong định giá đất ở, trong đó cách tiếp cận sử dụng lý thuyết Vị thế - Chất lượng (VT-CL) đang ngày càng được quan tâm.

Lý thuyết VT-CL đã đưa ra được những định hướng xây dựng cơ sở khoa học và phương pháp định giá bất động sản phù hợp với cơ chế thị trường [10]. Lý thuyết cũng khẳng định các đô thị có cấu trúc (đa) cực. Trong đó có một hay nhiều cực thể hiện những điểm cao nhất của một số loại vị thế xã hội nhất định, được công nhận bởi một phần nhất định của công chúng. Các cực vị thế có tác động rất lớn đến giá của các bất động sản ở gần đó, vì vậy chúng có thể được hiểu như các "cực tác động" trong định giá bất động sản. Xác định cực vị thế là bước quan trọng trong phương pháp định giá đất theo tiếp cận VT-CL [3]. Chỉ ra các cực vị thế sẽ giúp giải thích rõ hơn các yếu tố tác động đến giá đất và làm tăng hiệu quả của công tác định giá đất truyền thống.

Lý thuyết VT-CL cũng đang nhận được nhiều sự quan tâm của nhiều nhà khoa học trên thế giới. Wang Jun (2006) đã tìm hiểu và phân tích về phong cách sống và sự lựa chọn nơi ở tại Thượng Hải [12]. Moon-Jeong Kim (2010) đã ứng dụng lý thuyết để phân tích sự lựa chọn nhà giữa các hộ gia đình trên địa bàn thành phố Franklin, bang Ohio nước Mỹ [9]. Tổ chức SUME (2011) đã dựa trên các luận điểm của lý thuyết VT - CL để làm xuất phát điểm cho một dự án về nghiên cứu phát triển bền vững [11].

Tại Việt Nam, Hoàng Hữu Phê và nnk (2014) đã thực hiện điều tra khảo sát thu thập số liệu và tính toán chỉ số giá nhà và bất động sản ứng dụng lý thuyết VT-CL [5]. Đối với phân khúc địa lý, nhóm tác giả đã đề xuất các cực vị thế là Hồ Gươm, Hồ Tây và khu vực Trung Hòa - Nhân Chính. Đây đều là những khu vực có giá trị bất động sản ở mức cao so với các khu vực khác tại Hà Nội. Hà Văn Dũng và nnk (2016) đã ứng dụng lý thuyết VT-CL trong xác định các nhân tố ảnh hưởng tới giá bất động sản [1]. Nguyễn Mạnh Hùng và nnk (2008) đã ứng dụng lý thuyết vào công tác định giá bất động sản tại ba quận

Ngày nhận bài: 25/08/2020, ngày chuyển phản biện: 01/09/2020, ngày chấp nhận phản biện: 05/09/2020, ngày chấp nhận đăng: 10/09/2020 
của TP. Hồ Chí Minh: quận Thủ Đức, Bình Thạnh và Quận 1 với 350 mẫu điều tra [2].

Đối với khía cạnh về cực vị thế, hiện nay chưa có nghiên cứu nào đưa ra tiêu chí cụ thể cho việc nhận dạng các cực vị thế đối với giá đất ở đô thị. Cực vị thế đối với giá đất ở là những khu vực có tác động đáng kể tới giá đất trong khu vực và thông thường sẽ làm cho giá đất tăng lên. Cực vị thế đối với giá đất ở có thể được hình thành do các đối tượng tự nhiên, kinh tế - xã hội khác nhau trong mỗi khu vực như: hồ, công viên, $\mathrm{KĐT,...}$

Nếu xét một cách toàn diện thì việc phân loại rành mạch loại cực vị thế là không đơn giản vì sẽ phụ thuộc vào từng khía cạnh được xét đến. Theo lý thuyết VT-CL, các tham số vị thế có thể bao gồm: tài sản, văn hóa, kinh doanh, giáo dục,... Trong nghiên cứu này, 3 loại cực được đề xuất phân loại theo tiêu chí phát triển bền vững gồm: Kinh tế, Xã hội, Môi trường. Đây cũng đều là 3 nhóm tiêu chí mang tính đại diện, tổng hợp và được nhiều người công nhận.

\section{Phương pháp nghiên cứu}

Quy trình nhận dạng các cực vị thế đối với giá đất ở đô thị được thực hiện qua việc phối kết hợp các phương pháp nghiên cứu khác nhau. Sơ đồ quy được thể hiện trong hình 1 .

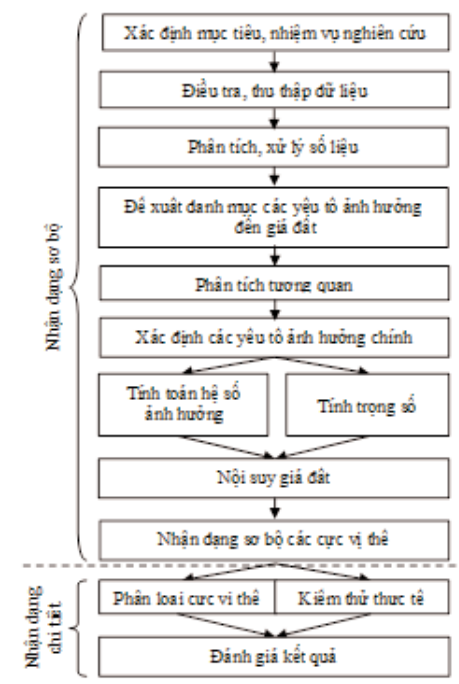

Hình 1: So đồ quy trình nhận dạng các cực vị thế đối với giá đất ở đô thị
Bước 1. Xác định mục tiêu, nhiệm vu nghiên cúu

Mục tiêu là đánh giá tổng thể và đánh giá chi tiết một số yếu tố ảnh hưởng chính đến giá đất ở đô thị. Từ đó xác định các nhiệm vụ cần nghiên cứu, dữ liệu, các phương pháp đánh giá,...

\section{Bước 2. Điều tra, thu thập dĩ liệu}

Các dữ liệu thu thập bao gồm dữ liệu sơ cấp, dữ liệu thứ cấp và dữ liệu bản đồ. Đối với dữ liệu sơ cấp, đề tài thực hiện thiết kế một bảng hỏi với các thông tin về thửa đất, nhà và các đặc điểm lân cận để tiến hành điều tra khảo sát thực địa.

\section{Bước 3. Phân tích, xử lý số liệu}

Đối với dữ liệu thuộc tính về giá đất, cần chọn lọc ra các mẫu giá đảm bảo yêu cầu, đủ độ tin cậy. Đối với những thửa đất không thu thập được thông tin riêng về giá đất thì sử dụng phương pháp triết trừ để loại bỏ giá của tài sản gắn liền với đất. Đối với dữ liệu không gian cần phải chuẩn hóa để dữ liệu này được thống nhất và đảm bảo độ chính xác.

Bước 4. Đề xuất danh mục các yếu tố ảnh hương tới giá đất

Có rất nhiều các yếu tố ảnh hưởng tới giá đất như: vị trí, diện tích,... [5,6] Các yếu tố này sẽ được phân chia thành 2 nhóm lớn là nhóm yếu tố về vị thế và chất lượng. Nhóm yếu tố về vị thế sẽ được phân nhóm nhỏ hơn là các nhóm về môi trường, kinh tế và xã hội. Tuy nhiên, các nhóm nhỏ này chỉ dùng để phân loại các cực vị thế mà không dùng để tính toán trọng số.

\section{Bước 5. Phân tích tương quan}

Phương pháp này được sử dụng để lựa chọn được những biến độc lập (các yếu tố ảnh hưởng tới giá đất) có tương quan chặt đến biến phụ thuộc (giá đất) căn cứ vào giá trị Sig. (significant - độ tin cậy) của kiểm định Pearson. Phân tích tương quan trong nghiên cứu này được thực hiện bằng mềm SPSS với dữ liệu đầu vào là các thông tin về mẫu giá được thu thập.

Bước 6. Xác định các yếu tố ảnh huởng chính 
Bước này nhằm lựa chọn những yếu tố có hệ số tương quan lớn cũng là yếu tố chính có ảnh hưởng mạnh tới giá đất.

\section{Bước 7a. Tính toán hệ số ảnh hưởng}

Từ những mẫu giá đã thu thập, dùng phương pháp so sánh cặp để cho điểm cho các hệ số ảnh hưởng. Mẫu giá được lựa chọn để tính toán là những thửa đất có giá đã được xác định, tương đồng hoặc đã được hiệu chỉnh cho tương đồng về các yếu tố cá biệt và đều những thửa đất có tính đại diện cho khu vực cần tính.

Ví dụ như để tính toán hệ số vị trí $K v t_{i}$ của các thửa đất, đề tài áp dụng công thức:

$$
K v t_{i}=\frac{G_{i}}{G_{1}}
$$

Trong đó: $G_{i}$ và $G_{1}$ : Giá đất thị trường trung bình của các thửa đất ở vị trí $i$ và vị trí 1 trong khu vực; $i=2,3,4$.

Các thửa đất này được lựa chọn theo tiêu chí tương đồng với nhau về các yếu tố cá biệt, trừ yếu tố vị trí.Từ đó ta tính tương tự sẽ có được hệ số cho từng vị trí của từng khu vực khác nhau.

Đối với các yếu tố về khoảng cách, đề tài sẽ sử dụng lý thuyết mờ fuzzy logic, kết hợp với ý kiến chuyên gia, ý kiến người dân trong quá trình điều tra khảo sát và tham khảo một số tài liệu có liên quan để phân khoảng và tính điểm.

Bảng 1: Hệ số phân khoảng khoảng cách đến KĐT lân cận

\begin{tabular}{|c|c|c|c|}
\hline $\begin{array}{l}\text { Khoảng } \\
\text { cách }\end{array}$ & $\begin{array}{l}0 \mathrm{~m}- \\
500 \mathrm{~m}\end{array}$ & $>500 \mathrm{~m}$ & $\begin{array}{l}\text { Với: } \\
+ \text { +) } x \text { là khoàng cách }\end{array}$ \\
\hline $\begin{array}{l}\text { Hệ số } \\
\text { ành } \\
\text { hường }\end{array}$ & 1 & $\frac{x_{\max }-x}{x_{\max }-500}$ & $\begin{array}{l}\text { từ thừa đất đến KĐT } \\
\text { +) } x_{\max } \text { Khoàng cách } \\
\text { của thừa đất xa nhất }\end{array}$ \\
\hline
\end{tabular}

Ví dụ với yếu tố khoảng cách đến khu đô thị (KĐT), theo Quy chuẩn kỹ thuật quốc gia - Quy hoạch xây dựng QCVN 01:2014/BXD, các công trình dịch vụ đô thị (trường học, công viên,...) được thiết kế cần đảm bảo có bán kính phục vụ không quá 500m. Đồng thời, sau khi tham vấn ý kiến chuyên gia và người dân quanh các KĐT trên địa bàn, nhóm tác giả nhận thấy khoảng cách từ $0-500 \mathrm{~m}$ sẽ là khoảng cách mà tầm ảnh hưởng của KĐT đến thửa đất là lớn nhất. Do vậy, việc phân khoảng và tính điểm được thực hiện như trong bảng 1 .

Cách tính này có thể được áp dụng đối với các KĐT và khu vực khác nhau nhưng giá trị khoảng cách trong công thức có thể thay đổi đối với từng khu vực nghiên cứu cụ thể.

\section{Bước 7b. Tính toán trọng số giữa các yếu tố}

Sử dụng phương pháp phân tích đa chỉ tiêu AHP, điểm số sẽ được đánh giá thông qua việc tham khảo ý kiến chuyên gia cũng như người dân địa phương. Kết quả sẽ được tổng hợp để làm cơ sở cho việc tính toán trọng số cho các yếu tố ảnh hưởng tới giá đất.

\section{Bước 8. Nội suy giá đất}

Trên thực tế, số lượng giao dịch thu thập được chỉ chiếm số lượng rất nhỏ so với tổng số lượng thửa đất giao dịch tại mỗi khu vực. Vì vậy, muốn ước tính được giá trị của các thửa đất còn lại, ta phải nội suy từ những thửa đã biết. Trong quá trình nội suy thì có sử dụng đến hệ số điều chỉnh và trọng số ở bước trước.

\section{Buớc 9. Nhận dạng sơ bộ các cực vị thế}

Dựa vào sự phân bố của giá đất cũng như các tiêu chí nhận dạng để có thể xác định sơ bộ cực vị thế. Khu vực nào có giá cao hơn đáng kể so với lân cận nhưng chất lượng của các thửa đất không quá nổi trội thì được coi là có khả năng có yếu tố tạo cực vị thế.

\section{Bước 10a. Phân loại cực vị thế}

Mỗi một thửa đất đã được gán các hệ số của mỗi yếu tố ảnh hưởng ở bước trước. Các yếu tố này thuộc 3 nhóm là kinh tế $(\mathrm{KT})$, xã hội $(\mathrm{XH})$ và môi trường $(\mathrm{MT})$. Phân loại cực vị thế bằng cách so sánh tổng hệ số ảnh hưởng của 3 nhóm. Công thức được thể hiện như sau:

$$
K_{V T}=\sum_{i=1}^{n}\left(W_{i} * k_{i}\right)
$$

Trong đó: $\mathrm{K}_{\mathrm{VT}}$ : là hệ số vị thế về $\mathrm{KT}, \mathrm{XH}$ hoặc MT; 
$\mathrm{W}_{\mathrm{i}}$ : Trong số của từng yếu tố $\mathrm{i}$;

$\mathrm{k}_{\mathrm{i}}$ : Giá trị hệ số của yếu tố i;

n: Tổng số yếu tố trong nhóm.

Như vậy tổng hệ số ảnh hưởng của nhóm nào cao thì khu vực đó sẽ có khả năng là chứa cực vị thế thuộc nhóm tương ứng.

Bước 10b. Kiểm thư thưc tế

Từ các kết quả đã phân tích, nghiên cứu tham khảo các nguồn tài liệu có liên quan kết hợp điều tra, khảo sát ý kiến người dân tại khu vực được cho là có yếu tố tạo cực vị thế để có đánh giá toàn diện và khách quan hơn.

Bước 11. Đánh giá kết quả

Bước này nhằm đánh giá lại kết quả của quá trình nhận dạng, phân loại cực và kiểm nghiệm lại quy trình đã làm để có sự điều chỉnh thích hợp cho các nghiên cứu tiếp theo.

\section{Khu vực nghiên cứu và dữ liệu}

\subsection{Giới thiệu về khu vưc nghiên cúu}

Là một quận nội thành của thành phố Hà Nội, Cầu Giấy có vị trí đặc biệt quan trọng trong phát triển kinh tế - xã hội, quốc phòng, an ninh của Thủ đô - cửa ngõ phía tây của thành phố [7].

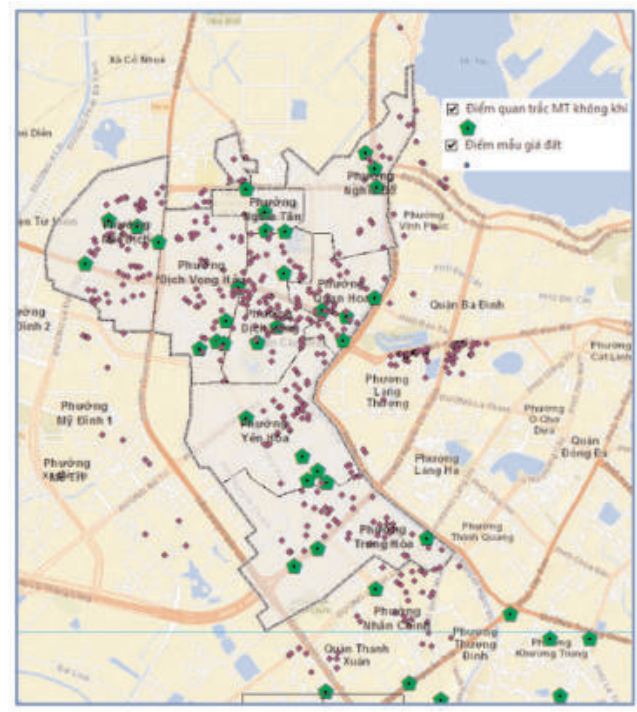

Hình 2: So đồ vị trí quận Cầu Giấy và vị trí các điểm lấy mẫu

\subsection{Dũ liệu}

Dữ liệu bản đồ: Bản đồ địa chính dạng số của 8 phường thuộc quận Cầu Giấy được đo vẽ và thành lập năm 2018, tỷ lệ 1/500. Nhóm nghiên cứu tiến hành chuẩn hóa các lỗi về không gian (topology), thông tin thuộc tính trong phần mềm Microstation và ArcGIS.

Dữ liệu giá đất thị trường: Được lấy từ các phiếu điều tra được khảo sát thực địa. Sau khi lọc loại bỏ một số mẫu không đáp ứng đủ điều kiện, tổng số mẫu được sử dụng là 452 mẫu.

Dữ liệu về hiện trạng môi trường: Được thu thập từ các báo cáo về công tác bảo vệ môi trường năm 2018 của quận Cầu Giấy [8].

\section{Kết quả nghiên cứu và thảo luận}

\subsection{Danh mục các yếu tố ảnh hưởng tới giá đất ở đô thị trên địa bàn quận Cầu Giẩy}

Từ kết quả điều tra khảo sát thực địa, ý kiến chuyên gia và tham khảo một số tài liệu có liên quan $[5,6]$, đề tài đề xuất danh mục dự kiến các yếu tố ảnh hưởng tới giá đất ở đô thị trên địa bàn nghiên cứu. Trong đó, các yếu tố về khoảng cách được được tính theo dựa theo đường giao thông. (Xem bảng 2)

\subsection{Xác định hệ số ảnh hưởng}

Kết quả thực hiện phân tích tương quan cho ta thấy những biến có ảnh hưởng chính tới giá đất là: $\mathrm{DT}, \mathrm{VT}, \mathrm{CD}, \mathrm{HD}, \mathrm{Bus}, \mathrm{TMD}, \mathrm{VH}, \mathrm{Ho}$, $\mathrm{TH}, \mathrm{CV}$ (bảng 3). Sau đó, các yếu tố này được tính trọng số bằng phương pháp $\mathrm{AHP}$ (bảng 3 ).

Để các hệ số phản ánh chính xác nhất sự ảnh hưởng của các yếu tố đối với mỗi thửa đất, đề tài chia khu vực nghiên cứu ra thành 3 khu vực nhỏ theo các tuyến đường. Khu vực được chia dựa vào bảng phân loại đường phố theo Quyết định số 31/2010/QĐ-UBND của UBND thành phố Hà Nội và sự tương đồng về điều kiện hạ tầng, kinh tế - xã hội và giá đất điều tra tại khu vực trong quá trình điều tra, khảo sát thực địa. Đối với các yếu tố về khoảng cách, nhóm tác giả sử dụng lý thuyết mờ đã được trình bày tại phần 2 . (Xem bảng 4) 
Bảng 4: Hệ số ảnh hưởng của một số yếu tố theo tìng khu vục

\begin{tabular}{|c|c|c|c|c|}
\hline Tên yếu tố & Phân loai & Khu vực 1 & Khu vưc 2 & Khu vực 3 \\
\hline \multirow{4}{*}{ Vị trí } & Vi tri 1 & 1 & 1 & 1 \\
\hline & Vị tri 2 & 0,91 & 0,87 & 0.89 \\
\hline & Vi tri 3 & 0,86 & 0.75 & 0.60 \\
\hline & Vi tri 4 & 0,71 & 0.59 & 0.47 \\
\hline \multirow{3}{*}{ Diện tích } & $<50 \mathrm{~m}^{2}$ & 0.93 & 0.95 & 0.98 \\
\hline & $50-80 \mathrm{~m}^{2}$ & 1 & 1 & 1 \\
\hline & $>80 \mathrm{~m}^{2}$ & 0.89 & 0.85 & 0.91 \\
\hline \multirow{3}{*}{ Cấp đường } & Cấp 2 & \multicolumn{3}{|c|}{1} \\
\hline & Cầ 3 & \multicolumn{3}{|c|}{1} \\
\hline & Cầp 4 & \multicolumn{3}{|c|}{0.88} \\
\hline
\end{tabular}

\section{thế}

4.3. Nội suy giá đất, nhận dạng sơ bộ cụcc vị

Từ 452 điểm mẫu giá thu thập được, tiến hành nội suy giá cho tất cả các thửa đất trên địa bàn nghiên cứu. Nhóm tác giả nhận thấy có hai khu vực có giá đất ở mức cao so với mặt bằng chung của quận và có nhiều yếu tố có thể trở thành một cực vị thế là: Khu vực xung quanh công viên Cầu Giấy và KĐT Trung Hòa - Nhân Chính. Các thửa đất ở tại KĐT Trung Hòa Nhân Chính có mức giá trung bình cao nhất, khoảng trên $350 \mathrm{tr} / \mathrm{m}^{2}$. Còn đối với khu vực xung quanh công viên Cầu Giấy, giá đất trung bình khoảng $250 \mathrm{tr} / \mathrm{m}^{2}$ (hình 3 ).

\subsection{Phân loại các cụ̂c vị thế, kiểm thử thục tế và đánh giá kết quả}

Đa số các thửa đất tiếp giáp với khu vực công viên Cầu Giấy có hệ số vị thế về môi trường cao hơn các hệ số vị thế về kinh tế và hệ số vị thế về xã hội. Các thửa đất ở khu vực KĐT Trung Hòa - Nhân Chính có hệ số vị thế về xã hội cao hơn các hệ số còn lại.

Nhóm nghiên cứu thực hiện phỏng vấn nhanh với 72 mẫu phiếu tại 2 khu vực được xác định là cực vị thế.

\section{* Khu vực công viên Cầu Giấy}

Hầu hết tất cả người dân được hỏi cùng chung quan điểm rằng công viên Cầu Giấy là địa điểm có ý nghĩa lớn về khía cạnh môi trường.

\section{* Khu vục KĐT Trung Hòa - Nhân Chính}

Hầu như những người được hỏi đều cho rằng, khu đô thị mang lại nhiều yếu tố thuận lợi cho người dân. Tuy nhiên vẫn có một số ý kiến phàn nàn về chất lượng của một số công trình đã xuống cấp do KĐT đã xây dựng từ lâu và làm KĐT trở nên ít có sức hút hơn.

Như vậy, dựa vào những đặc điểm, sự ảnh hưởng đến giá đất mà nhóm nghiên cứu đã phân loại công viên Cầu Giấy là cực vị thế về môi trường, khu đô thị Trung Hòa - Nhân chính là cực vị thế về xã hội. Các kết quả này càng được khẳng định rõ hơn qua các phiếu khảo sát người dân tại 2 khu vực trên. Trong những nghiên cứu tiếp theo, nhóm tác giả nhận thấy có thể thử nghiệm xác định đầy đủ hơn các yếu tố ảnh hưởng tới giá đất trong khu vực cũng như có thể tiếp cận cách thức tính trọng số theo phương pháp khác (ví dụ như phương pháp ANP) để có được kết quả tối ưu hơn. (Xem hình 3)

\section{Kết luận}

Nghiên cứu đã đưa ra một số cơ sở cho việc nhận các cực vị thế đối với giá đất và đề xuất quy trình nhận dạng cực vị thế đối với giá đất ở. Trên cơ sở phân tích, xử lý dữ liệu của 452 điểm mẫu giá, nhóm tác giả đã chỉ ra được 02 cực vị thế đối với giá đất ở đô thị tại khu vực nghiên cứu là công viên Cầu Giấy là cực vị thế thiên về ảnh hưởng môi trường và khu đô thị mới Trung Hòa - Nhân Chính là cực vị thế thiên về ảnh hưởng xã hội.

Từ những kết quả nghiên cứu đã đạt được, tác giả xin kiến nghị các cơ quan, các nhà chuyên môn khi tiến hành định giá đất, cần lưu ý thêm các yếu tố về cực vị thế vì đây thường là các yếu tố có ảnh hưởng đáng kể tới giá đất trong khu vực. $\bigcirc$

\section{Lời cảm ơn}

Nghiên cứu này được tài trợ bởi Trường Đại học Khoa học Tự nhiên trong đề tài mã số TN.19.12.

\section{Tài liệu tham khảo}

[1]. Hà Văn Dũng, Phùng Thị Thu Hà (2016), Xác định các nhân tố ảnh hưởng đến giá bất động sản, Tạp chí Tài chính, kỳ 1 tháng 11/2016.

[2]. Nguyễn Mạnh Hùng, Trần Thanh Hùng, 
Bảng 2: Đề xuất các yếu tố ảnh hưởng đến giá đất ở đô thị

\begin{tabular}{|c|c|c|c|c|c|}
\hline STT & Ký hiệu & \multicolumn{2}{|c|}{ Nhóm yếu tố } & Mô tả yến tố ảnh hường & Cách xác định \\
\hline 1 & VT & \multirow{3}{*}{ Kinh tế } & \multirow{3}{*}{ Kinh tế } & $\begin{array}{l}\text { Vị trí của thưa đất phân loại theo Quyêt định số } \\
\text { 30/2019/QD-UBND cua UBND thành phô HN }\end{array}$ & \multirow{2}{*}{$\begin{array}{l}\text { Select by } \\
\text { location trong } \\
\text { ArcGIS }\end{array}$} \\
\hline 2 & $C D$ & & & $\begin{array}{l}\text { Cấp đường dựa theo Quyết định số 31/2010/QĐ- } \\
\text { UBND của UBND thảnh phô Hà Nội. }\end{array}$ & \\
\hline 3 & Cho & & & $\begin{array}{l}\text { Khoảng cách tính theo đường giao thông từ thửa đất } \\
\text { đền chợ lớn gân nhất. }\end{array}$ & \multirow{12}{*}{$\begin{array}{l}\text { Công cụ } \\
\text { Network } \\
\text { Analyst trong } \\
\text { ArcGIS }\end{array}$} \\
\hline 4 & $\mathrm{TH}$ & \multirow{11}{*}{ Vị thế } & \multirow{9}{*}{ Xã hội } & $\begin{array}{l}\text { Khoảng cách tính theo đường giao thông từ thửa đất } \\
\text { đên trường học gân nhât }\end{array}$ & \\
\hline 5 & BV & & & 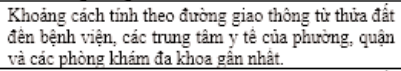 & \\
\hline 6 & TMD & & & $\begin{array}{l}\text { Khoảng cách tính theo đường giao thông từ thửa đất } \\
\text { đên trung tâm thương mai, siếu thi gân nhât. }\end{array}$ & \\
\hline 7 & $\mathrm{KDC}$ & & & $\begin{array}{l}\text { Khoảng cách tính theo đường giao thông từ thữa đất } \\
\text { đên khu đô thị lớn gấn nhât. }\end{array}$ & \\
\hline 8 & Bus & & & $\begin{array}{l}\text { Khoảng cách tính theo đường giao thông từ thứa đất } \\
\text { tram xe bus gân nhất. }\end{array}$ & \\
\hline 9 & Dinh & & & $\begin{array}{l}\text { Khoảng cách tính theo đường giao thông từ thứa đất } \\
\text { đền đinh, chùa gân nhất. }\end{array}$ & \\
\hline 10 & UBND & & & $\begin{array}{l}\text { Khoảng cách tính theo đường giao thông từ thửa đất } \\
\text { đên UBND gân nhât. }\end{array}$ & \\
\hline 11 & $\mathrm{CA}$ & & & $\begin{array}{l}\text { Khoảng cách tính theo đường giao thông từ thữa đất } \\
\text { đên trư sớ công an gấn nhât. }\end{array}$ & \\
\hline 12 & $\mathrm{VH}$ & & & $\begin{array}{l}\text { Khoảng cách tính theo đarờng giao thông từ thưa đất } \\
\text { đên trung tâm văn hóa, nghệ thuật, bảo tàng, nhà } \\
\text { hát, thê thao gần nhât. }\end{array}$ & \\
\hline 13 & $\mathrm{CV}$ & & \multirow{2}{*}{$\begin{array}{l}\text { Môi } \\
\text { trương }\end{array}$} & $\begin{array}{l}\text { Khoảng cách tính theo đường giao thông từ thử đất } \\
\text { đên khu công viên lớn, các khu vực thông thoáng, } \\
\text { các sân choi trong các khu chung cư lớn. }\end{array}$ & \\
\hline 14 & Ho & & & $\begin{array}{l}\text { Khoỏing cách tính theo đường giao thông tì thira đất đền } \\
\text { hố nước gân nhât. }\end{array}$ & \\
\hline 15 & SQU & \multirow{6}{*}{\multicolumn{2}{|c|}{ Chất lượng }} & Diện tích thửa đất & \multirow{4}{*}{$\begin{array}{l}\text { Bản đồ địa } \\
\text { chính }\end{array}$} \\
\hline 16 & $\mathrm{HD}$ & & & Hinh dáng thừa đất & \\
\hline 17 & MT & & & Độ rộng mặt tiền của thửa đất & \\
\hline 18 & $\mathrm{CS}$ & & & Chiều sâu của thửa đất & \\
\hline 19 & Bui & & & Là mức độ ô nhiễm không khi về bụi lo lưmg & \multirow{2}{*}{ Nội suy IDW } \\
\hline 20 & On & & & Là mức độ ô nhiễm không khí về tiếng ồn & \\
\hline
\end{tabular}

Bảng 3: Ma trận trọng số chung của các yếu tố

\begin{tabular}{|c|c|c|c|c|c|}
\hline STT & Yếu tố & Nhóm & $\begin{array}{c}\text { Trọng số từng yếu tố } \\
\text { trong nhóm }\end{array}$ & $\begin{array}{c}\text { Trọng số } \\
\text { nhóm }\end{array}$ & $\begin{array}{c}\text { Trọng số } \\
\text { chung }\end{array}$ \\
\hline 1 & VT & \multirow{9}{*}{$\mathrm{Vị}_{\text {ị }}$ thế } & 0.222 & \multirow{9}{*}{0.8} & 0.177 \\
\hline 2 & $\mathrm{CD}$ & & 0.107 & & 0.086 \\
\hline 3 & Bus & & 0.033 & & 0.026 \\
\hline 4 & TMD & & 0.156 & & 0.125 \\
\hline 5 & $\mathrm{VH}$ & & 0.048 & & 0.039 \\
\hline 6 & Ho & & 0.107 & & 0.086 \\
\hline 7 & Cho & & 0.062 & & 0.049 \\
\hline 8 & $\mathrm{TH}$ & & 0.093 & & 0.074 \\
\hline 9 & $\mathrm{CV}$ & & 0.173 & & 0.138 \\
\hline 10 & DT & \multirow{2}{*}{ Chất lượng } & 0.333 & \multirow{2}{*}{0.2} & 0.067 \\
\hline 11 & $\mathrm{HD}$ & & 0.667 & & 0.133 \\
\hline
\end{tabular}

Bảng 5: Hệ số đối với một số yếu tố về khoảng cách

\begin{tabular}{|c|c|c|c|c|}
\hline $\begin{array}{c}\text { Tên } \\
\text { yếu tố }\end{array}$ & & $\begin{array}{l}\text { ông thức tính hệ số } \\
\text { ảnh hường }\end{array}$ & $\begin{array}{c}\text { Tên } \\
\text { yếu tố }\end{array}$ & $\begin{array}{c}\text { Công thức tính hệ số } \\
\text { ảnh hưởng }\end{array}$ \\
\hline $\begin{array}{l}\text { Bus, } \\
\text { Ho }\end{array}$ & $f(x)=$ & $\left\{\begin{aligned} \frac{1}{x \max -x} 0<x & \leq 300 \\
\frac{x \max -500}{x} & >300\end{aligned}\right.$ & $\begin{array}{l}\text { TMD, } \\
\text { VH, } \\
\text { TH, CV }\end{array}$ & $f(x)=\left\{\begin{array}{cr}1 & 0<x \leq 500 \\
\frac{x \max -x}{x \max -500} \quad x>500\end{array}\right.$ \\
\hline Cho & $f(x)=$ & $\left\{\begin{array}{lr}\frac{x}{100} & 0<x<100 \\
1 & 100 \leq x \leq 500 \\
\frac{x \max -x}{x \max -500} x>500\end{array}\right.$ & & \\
\hline
\end{tabular}


Hoàng Hữu Phê (2008), Phương pháp định giá bất động sản ứng dụng lý thuyết vị thế - chất lượng, Tạp chí Địa chính, số 3, tháng 6/2008, Hà Nội.

[3]. Trần Thanh Hùng (2014), Nguyên lý bất định và lý thuyết Vị thế - Chất lượng: Triển vọng ứng dụng trong nghiên cứu quản lý đất đai, Hội nghị Khoa học Công nghệ lần 2 "Tài nguyên, năng lượng và Môi trường vì sự phát triển bền vững, Hồ Chí Minh”.

[4]. Hoàng Hữu Phê, Trần Thanh Hùng, Nguyễn Thị Mỹ Linh (2013), Lý thuyết vị thế chất lượng và các ứng dụng chính sách trong phát triển đô thị và thị trường bất động sản, Tạp chí Kiến trúc Việt Nam, Bộ Xây dựng, Hà Nội, số tháng 6/2013.

[5]. Hoàng Hữu Phê (2015), Báo cáo tổng hợp dự án "Điều tra khảo sát thu thập số liệu và tính toán chỉ số giá nhà và bất động sản ứng dụng lý thuyết vị thế - chất lượng", Hà Nội.

[6]. Nguyễn Phi Sơn và nnk (2015), Nghiên cứu phương pháp xây dựng bản đồ vùng giá trị đất khu vực đất phi nông nghiệp ở đô thị bằng mô hình thống kê và công nghệ GIS, báo cáo tổng hợp đề tài nghiên cứu khoa học cấp Bộ TN\&MT, Hà Nội.
[7]. UBND quận Cầu Giấy (2018), Báo cáo kết quả thực hiện nhiệm vụ phát triển kinh tế xã hội năm 2018 của quận Cầu Giấy, Hà Nội.

[8]. UBND quận Cầu Giấy (2018), Báo cáo công tác bảo vệ môi trường năm 2018 tại quận Cầu Giấy, Hà Nội.

[9]. Moon-Jeong Kim (2010), Residential location decisions: Heterogeneity and the Tradeoff between location and housing quality, Dissertation, The Ohio State University.

[10]. Phe, H.H, Wakely, P.(2000), Status, Quality and the Other Trade-Off: Towards a new theory of Urban Residential Location. Urban Studies, 37(1), 7-35. Taylor \& Francis. The Donald Robertson Memorial Prizewinner 2000.

[11]. Sustainable Urban Metabolism For Europe (SUME) (2009), Development process, urban form and metabolism, Understanding the interface between actors, institutions, structures and mechanisms, SUME, Working paper 4.1.

[12]. Wang Jun (2006), Lifestyle and housing location choice - a case study of residential differentiation of professionals in transitional Shanghai, a thesis for the degree of Doctor of Philosophy, University of Hong Kong. $\bigcirc$
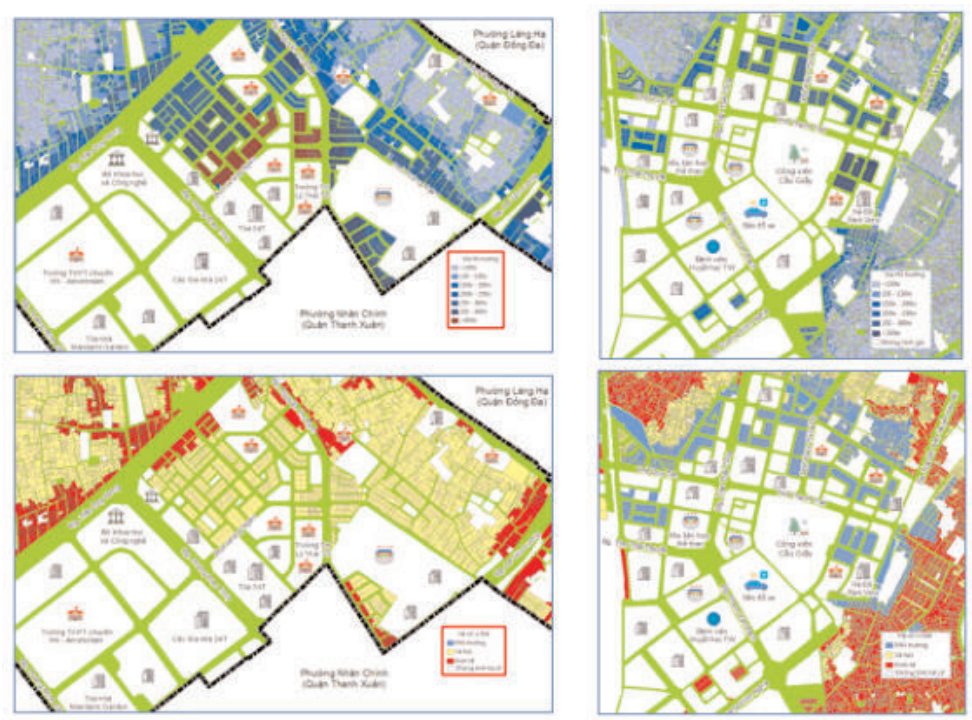

Hìn 3: Kết quả nọi suy giá thị trường và so đồ phân bố các hệ số vị thế chiếm ưu thế tại hai khu vực KĐT Trung Hòa - Nhân Chính (ảnh trái) và công viên Cầu Giấy (ảnh phải) 


\section{Summary}

Research on identification of status poles for urban residential land prices in Cau Giay District according to Status - Quality Trade Off (SQTO) approach

Bui Ngoc Tu, Le Phuong Thuy, Pham Le Tuan, Tran Quoc Binh

Faculty of Geography, VNU University of Science, 334 Nguyen Trai, Hanoi, Vietnam

Evaluating residential land prices plays an important role in the financial management. Currently, there are different approaches to evaluate residential land prices, including the one that uses Status - Quality Trade Off (SQTO) theory. Identifing status poles is an important step in the land valuation method based on SQTO approach. This study aims to identify status poles for urban residential land prices in Cau Giay District. With 452 samples collected in recent years and proposed 20 factors affecting land price, the authors have pointed out two status poles urban residential land prices, namely Cau Giay park and Trung Hoa - Nhan Chinh new urban area. $\bigcirc$

\section{NGHIÊN CỨU TÍNH TOÁN VÀ MÔ HÌNH HÓA.......}

(Tiếp theo trang 29)

[9]. TCVN 4048:2011. Chất lượng đất - phương pháp xác định độ ẩm và hệ số khô kiệt.

[10]. TCVN 7538-1:2006. Chất lượng đất - lấy mẫu

[11]. Zhang. D. \& Zhou, G. (2016). Estimation of Soil Moisture from Optical and Thermal Remote Sensing: A Review. Sensors, p. 16, 1308. Doi:10.3390/s16081308.O

\section{Summary}

\section{Estimating and distribution mapping of moisture content of topsoils over the Northern Central Highlands of Vietnam using Sentinel 2A Imagery}

Ngo Thi Dinh, Land management and rural development institute - Forestry University

Pham Quang Vinh, The International Center for Tropical Agriculture (CIAT)

Nguyen Thi Thu Ha, University of Science, Vietnam National University

This study aims to estimate the soil moisture content (SMC) of topsoils over the Northern Central Highland using the Sentinel 2A image basing on the development of a regional emprirical model for the estimation. Total 8 soil samples representating for 6 soil types in the study area were collected and sub-sampled into 80 samples with 10 interval SMC levels for each sample. Resultant soil spectral analysis indicated a high correlation of SMC and the ratio of S2A band 8 (NIR, $865 \mathrm{~nm}$ ) versus band 12 (SWIR2, $2190 \mathrm{~nm}$ ), therefore the SMC can be accurately estimated from the ratio with a logarithm function. Applications of the model into estimating SMC from $30 \mathrm{~S} 2 \mathrm{~A}$ scenes acquired over the study area in March 5 years, since 2016 to 2020, show that the 2016 drought is severer than the other year droughts. In March 2016, a one-third of the study area was coverered by topsoils with SMC lower than 25\%. The attention on the correlation between SMC in topsoils which are coverered by vegetation and un-vegetation should be focused in the future for futher application in the agricultural drough management. $\mathrm{O}$ 